\title{
Analytical Study for Some Variables of the Stride and Performance Level for the Racewalkers
}

\author{
Professor Dr. Hesham Sayed Ahmed ${ }^{1}$, Professor Dr. Atef Sayed Ahmed ${ }^{2}$
}

${ }^{1}$ Professor of Athletics, Department of Physical Education, Umm Al-Qura University

${ }^{2}$ Professor of Athletics, Department of Theories and Applications Athletics, University of Sadat City

Abstract

This study aims to identify the relationship between the angle of foot rotation at pushing off, the length of the stride and the time of performance for racewalkers. The sample consisted of (10) racewalkers who participated in the Egyptian racewalk championship in Cairo stadium from 28-30 October 2015. The average age, height and weight were: (26.20 \pm 3.99 years-old $),(171.50 \pm 3.54 \mathrm{~cm})$ and $(67.10 \pm 3.07 \mathrm{~kg})$ respectively. The results showed that here is a significant correlation between the angle of foot rotation at pushing off and the time of performance, as well as the speed of performance, length of stride and stride frequency, also there is a non-significant correlation between the angle of foot rotation at pushing off and the timing of the stride.

Keywords: Biomechanics, angle of foot rotation at pushing-off, performance level, racewalkers

\section{Introduction}

Racewalking is progressive striding executed while contacting the ground continuously, as the front foot contacts the ground before the back foot is lifted, and it is better not bending the knee when performing the columnar position (IAAF competition rule, no. 230, 2014)

This rule was introduced in 1995, and before 1995 the leg had to be straightened in a vertical position. The athletes had to develop the pattern of the special movements' characteristics which is known as "race walking style", although it has been used worldwide by all athletes. (Pavei, et al, 2012)

The stride length of the world's best racewalkers ranges between
$2.44 \mathrm{~m}$ and $2.72 \mathrm{~m}$ (for men). (Hanley, B. et al, 2008)

It is important to determine the variations in the angles of the upper and lower limb joints, and each individual's points of strength and weakness to achieve the best performance for each racewalker.

The gait cycle has two strides a left stride and a right stride. The basic description of the gait cycle is the cycle that includes a complete stride, the length of a single stride, and the foot angles. The length of the full distance stride is between the two successive heel contacts of the same foot, while the length of one stride is the distance between the two successive heel contacts of the two different feet. The main factor 
that describes a gait cycle is the stride frequency (stride rate), and there is another factor to describe the gait cycle which is the stride time (full distance gait cycle), single stride time (the time of executing one stride with either the right or the left foot), speed of walking. A gait cycle can be divided into two major phases: the pulling phase which forms about $60 \%$ of the gait cycle (from the contact of the right heel to the right toe off) and the swing phase which forms about $40 \%$ of the gait cycle (from the right toe off to the next right heel contact). (Donald A. Neumann, 2010, pp631637)

The principal aim of the relatively large amounts of pelvic rotation is to place the feet along a straight line to assist in increasing the stride length.

The stride width is sometimes referred to as the walking base or base of support (Levine et al., 2012). By contrast, by keeping the stride width narrow, less lateral movement is needed to maintain balance and therefore muscular energy is reduced (Levine et al., 2012). The normal width of the stride usually ranges between 5 and $13 \mathrm{~cm}$ (Levine et al., 2012).

The ankle is obviously an important joint in all forms of gait. Its orientation can be defined by a line passing between the tips of the medial and lateral malleoli (Czerniecki, 1988), and Cairns et al. (1986). The normal state of the foot is when the ankle at $110^{\circ}$; as the angles get greater than this with plantarflexion and the angles get lesser with dorsiflexion. The range of ankle dorsiflexion during late swing was greater in the competitive pace condition $\left(27^{\circ} \pm 7\right)$ than in normal walking, fast walking or running. The ankle joint is also considered important in late stance as plantarflexion aids the drive phase of the stride and the plantarflexion angle at toe-off in race walking was found to be higher than in normal walking (Preatoni et al., 2006).

Domestic researches on the athletic sports by kinematics and biomechanics have been continuously carried out in various forms such as the researches related to analysis of stride length, stride time, stride length, flight time, stride frequency, knee angle at contact, hip angle, pelvic rotation, shoulder rotation, leg pathway deviation, speed, performance time.

Therefore, the researcher conducted this study to identify the relationship between the angle of foot rotation at pushing off and the stride length and the time of performance for racewalkers.

This study aims to identify the relationship between the angle of foot rotation at pushing off and the stride length and the time of performance for racewalkers. 


\section{Methods}

The researcher analyzed the stride of the racewalking competitors who participated in the republic's competition of Egyptian racewalk championship in Cairo stadium from 28-30 October 2015.

\section{Sample:}

The sample consisted of (10) racewalkers from the Egyptian racewalk championship in Cairo stadium from 28-30 October 2015, the average age was $(26.20 \pm 3.99$ years-old), body height (171.50 \pm $3.54 \mathrm{~cm})$ and body mass $(67.10 \pm$ $3.07 \mathrm{~kg})$.

\section{Data collecting tools}

Data analysis: Dartfish v4.5 program was used to calculate the data. Racewalking speed was determined as the mean horizontal

\section{Results:}

Table ( 1 ) Race walking performance and some variables of stride for walker parameters ( Time of Performance, Speed of performance, Stride length, stride frequency, Stride Time and Angle of foot Rotation at the push ).

\begin{tabular}{lcc}
\hline & Mean & SD. \\
\hline Time of Performance ( min. ) & 106.99 & 11.87 \\
\hline Speed of performance ( m/s) & 1.89 & 0.20 \\
\hline Stride length ( m. ) & 2.15 & 0.15 \\
\hline stride frequency ( HZ) & 3.01 & 0.16 \\
\hline stride time ( s. ) & 0.46 & 0.10 \\
\hline Angle of Rotation foot at push $\left({ }^{\circledR}\right)$ & 21.40 & 3.95 \\
\hline
\end{tabular}


Table ( 2 ) The relationship between Angle of foot rotation at the push on some variables of stride and performance for walker ( Time of Performance, Speed of performance, Stride length, stride frequency, Stride Time and Angle of foot Rotation at the push ).

\begin{tabular}{lcccccc}
\hline & $\begin{array}{c}\text { Time of } \\
\text { Performance }\end{array}$ & $\begin{array}{c}\text { Speed of } \\
\text { Performance }\end{array}$ & Stride length & $\begin{array}{c}\text { Stride } \\
\text { Frequency }\end{array}$ & Stride time & $\begin{array}{c}\text { Angle of } \\
\text { Rotation foot }\end{array}$ \\
\hline Time of Performance & & $-.997^{* *}$ & $-.947^{* *}$ & $-.911^{* *}$ & $-.691^{*}$ & $.746^{*}$ \\
\hline
\end{tabular}

\begin{tabular}{|c|c|c|c|c|}
\hline Speed of performance & $.940^{* *}$ & $.919^{* *}$ & $.714^{*}$ & $-.739^{\star}$ \\
\hline Stride length & & $.791^{* \star}$ & .625 & $-.649^{*}$ \\
\hline Stride frequency & & & $.801^{* *}$ & $-.651^{*}$ \\
\hline Stride time & & & & -.222 \\
\hline Angle of Rotation foot & & & & \\
\hline
\end{tabular}

$\mathrm{P}>0.05$

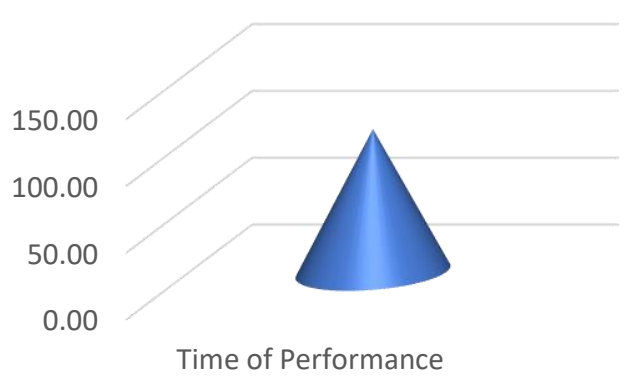

Fig. ( 1 ) Race walking Time of Performance

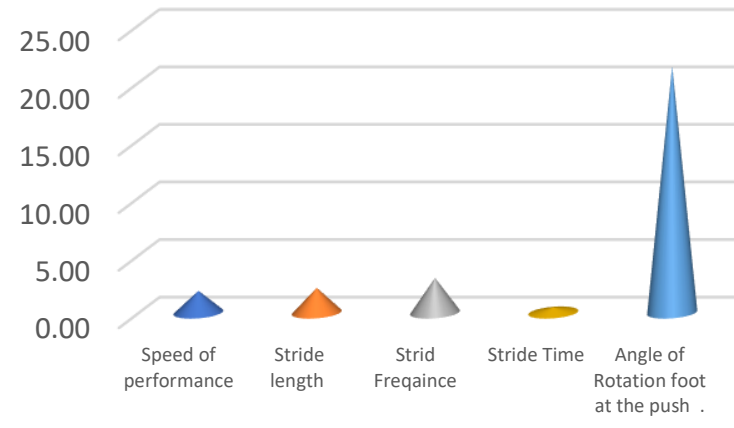

Figure ( 2 ) Some variables of stride for race walking ( Speed of performance, Stride length, stride frequency, Stride Time and Angle of foot Rotation at push)

\section{Discussion :}

Table (1), and figures (1) and (2) show the average performance of the stride variables in racewalk, performance time and speed, they also show the average time of performance (106.99), speed of performance (1.89), stride length (2.15), stride frequency (3.01), stride time (0.46) and angle of foot rotation at pushing (21.40).

Table (2) shows the relationship between the angle of foot rotation at pushing on the stride variables of racewalk, as there is a statistically significant correlation between the angle of foot rotation at pushing with the time of performance, speed of performance, length of stride and stride frequency, while there is no significant correlation between the angle of foot rotation at pushing and the stride time. 
The researcher believes that this happens when the value of the angle of foot rotation decreases by the time. This confirms that the value of the angle improves the pushing phase of the foot forward, followed by improvement in the speed of performance, length of stride, and stride frequency.

The rotation of the foot also leads to increasing the pelvis circulation as well as the shoulder circulation and thus the performance time decreases in case the pelvis movement was extreme.

These findings of the importance of stride length conform to the results of the men's $20 \mathrm{~km}$ players, also there was a positive relation between the stride length and stride frequency with the results of HANLEY, B.; BISSAS, A. \& DRAKE, A. (2011), ( HANLEY, B. \& BISSAS, A. (2012).

The distance of the support foot at toe-off is important in generating adequate stride length and forward propulsion (HOGA et al., 2003).

\section{Recommendations:}

- Improving the movement of the foot by decreasing the value of the foot angle by the foot exercise, and walking in the line.

- Improving the angle of foot rotation can help reducing the injuries that may occur in the ankle or the knee joints.
- Avoiding the movement patterns that may lead to a high risk of ankle injury during the swing and early stance.

- Improving the role of the ankle as an important source of movement generation during stance, while the hip is important for movement generation during early swing, late swing, and early stance.

\section{References:}

1. Cairns, M. A., Burdette, R. G., Pisciotta, J. C. \& Simon, S. R. (1986) A biomechanical analysis of racewalking gait. Medicine and Science in Sports and Exercise, 18(4), pp.446-453.

2. Czerniecki, J. M. (1988) Foot and ankle biomechanics in walking and running. American Journal of Physical Medicine \& Rehabilitation, 67(6), pp.246-252.

3. Donald A. Neumann PhD PT FAPTA (2010) : Kinesiology of the Musculoskeletal System: Foundations for Rehabilitation, 2nd Edition, St. Louis, Missouri : Mosby.

4. Hanley B, Bissas A, Drake A. ( 2008 ) Initial findings of a biomechanical analysis at the 2008 IAAF World Race Walking Cup. New Stud Athlet 23(4): 2734.

5. HANLEY, B. \& BISSAS, A. (2012). Differences between body segment parameter models in 
analysing elite race walkers in competition, Gazzetta Medica Italiana, 171 (5): 541-550.

6. HANLEY, B.; BISSAS, A. \& DRAKE, A. (2011). Kinematic characteristics of elite men's and women's $20 \mathrm{~km}$ race walking and their variation during the race. Sports Biomechanics, 10 (2): 110124.

7. HOGA, K.; AE, M.; ENOMOTO, Y.; \& FUJII, N. (2003). Mechanical energy flow in the recovery leg of elite race walkers, Sports Biomechanics, 2(1):1-13.

8. International Association of Athletics Federation (2014). IAAF Competition rules 20142015. Retrieved from http://www.iaaf.org/aboutiaaf/documents/rulesregulations\#rules

9. McGovern, D. (2008) Racewalk speed, strength and technique exercises and drills. Walk! Magazine, 4(3), pp.22-24.

10.Preatoni, E., La Torre, A. \& Rodano, R. (2006) A biomechanical comparison between racewalking and normal walking stance phase. In: Schwameder, H., Strutzenberger, G., Fastenbauer, V., Lindinger, S. \& Müller, E. eds. Proceedings of the XXIV International Symposium on Biomechanics in Sports.
Salzburg: Universität Salzburg, pp.143-146.

11.Pavei, G., Cazzola, D., La Torre, A., \& Minetti, A. E. (2012). Body center of mass trajectory shows how race walkers elude "Froude law". n R., Meeusen, J., Duchateau, B., Roelands, M., Klass, B., De Geus, S., Baudry, \& E., Tsolakidis (Eds.), Book of Abstracts of the $17^{\text {th }}$ Annual Congress of the European College of Sport Science (pp. 42). Bruges: European College of Sport Science.

12.Salvage, J. \& Seaman, T. (2011) Race Walk Clinic - In a Book. Medford: Walking Promotions.

13.Levine, D., Richards, J. \& Whittle, M. W. (2012) Whittle's Gait Analysis (5th ed.). Edinburgh: Churchill Livingstone. 